https://www.journal-imab-bg.org

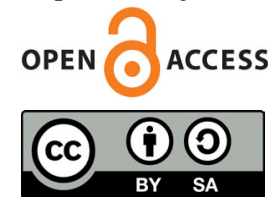

Original article

\title{
THYMUS PEPTIDES (THYMULIN, THYMOSIN ALPHA 1 AND THYMOSIN BETA 4) INHIBITING EFFECTS ON THE INTRINSIC BLOOD COAGULATION PATHWAY IN RATS
}

\author{
Negrin Negrev ${ }^{1}$, Kiril Hristosov ${ }^{2}$, Antoniya Hachmeryan ${ }^{1}$, Yuri Nyagolov ${ }^{3}$ \\ 1) Department of Physiology, Medical University, Varna, Bulgaria \\ 2) Department of Internal Diseases, Medical University, Varna, Bulgaria \\ 3) Department of Physiology, Medical University, Sofia, Bulgaria
}

\section{ABSTRACT:}

Thymus peptides (thymulin, thymosin alpha 1 and thymosin beta 4) inhibiting effects on the intrinsic blood coagulation pathway in rats

Background and purpose: Hemostasis is a basic homeostatic mechanism protecting the body from thrombosis or haemorrhage. A number of pathological conditions, including multiple endocrine disorders modulate the balance between pro- and anticoagulation factors and establish conditions of hyper- or hypocoagulability. Endocrine effects of thymus gland on blood coagulation are not completely elucidated, and data existing on the theme are relatively scarce and partially controversial. The present study was designed to investigate thymus peptides (thymulin, thymosin alpha 1 and thymosin beta 4) effects on key intrinsic pathway plasma clotting factors XII, XI, IX, X and activated partial thromboplastin time (aPTT) - a principal marker of blood coagulation via intrinsic pathway of hemocoagulation, in rats.

Materials and methods: Plasma clotting factor activities and aPTT were studied on 52 male Wistar intact rats after 3 day s.c. application of the thymic peptides envisaged using routine kinetic coagulometry.

Results of the study indicate a significant reduction of FXII activity by thymulin and thymosin alpha 1 , and FXI and FIX activity by thymulin and thymosin beta 4 .

Conclusion: Upper results support the conclusion that thymus peptides thymulin, thymosin alpha 1 and thymosin beta 4 application in rats imposes a distinct tendency of hypocoagulability.

Keywords: thymulin, thymosin alpha 1, thymosin beta 4 , aPTT, intrinsic pathway, hemocoagulation,

\section{INTRODUCTION:}

Hemostasis is a complex evolutionary mechanism involved in the maintenance of blood circulation integrity [1]. Procoagulant and anticoagulant factor disorders are commonly associated with a tendency of either haemorrhage or thrombosis [2]. The classic "cascade" model of blood coagulation activation includes two pathways: intrinsic and extrinsic [3]. Blood coagulation via the intrin- sic pathway is initiated by activation of plasma clotting factor XII (Hageman factor), involving high molecular weight kininogen, and plasma prekallikrein. Those three proteins are components of the so called contact system triggering coagulation process by contact activation [4]. Blood interaction with a negatively charged surface produces conformation changes in FXII and its activation to FXIIa. FXIIa converts prekallikrein to active $\alpha$-kallikrein which in turn activates additional quantities of FXII by a positive feedback [5]. Activated FXII catalyses the conversion f FXI to FXIa, with following activation of FIX to FIXa [6]. An "internal tanase complex" (FIXa/FVIIIa) is formed as a result leading to activation of FX. Activation of FX is the first step of the end common pathway of blood coagulation leading to thrombin generation terminating with blood clot formation [7]

The elements of the intrinsic system FIXa (in a combination of FVIIIa) and FXIa participate in reactions providing both blood clot formation and its resistance to fibrinolysis [8]. Dysregulation of the upper pathways modifies the haemostatic balance with the manifestation of clinical tendencies of either thrombosis or haemorrhage [9]. Activated partial thromboplastin time (aPTT) is an index highly dependent on factors of the intrinsic pathway of prothrombin activator formation [10]. Its evaluation is a basic integral clinical criterion for estimation of the activity of the principle factors of hemocoagulation via the intrinsic pathway [11].

Numerous environmental and endogenous factors have been postulated to participate in the maintenance of the hemostasis balance [12]. As far as endocrine mechanisms are concerned, there is a plenty of evidence for their direct effect on primary and secondary hemostasis [13]. Although a lot of studies have been focused on endocrine disorders and their effect on hemostasis [14] the role of the thymus gland and particularly the effect of thymus peptides on blood coagulation mechanisms still remain unclear. A lot of factors, including the limited number of studies, differences in the doses and duration of application, a limited number of hemostasis parameters evaluated, do not allow a precise assessment of the involvement of the thymus peptides in the hemostasis process [15]. 
The present study was designed to investigate the effects of thymus peptides thymulin, thymosin alpha 1 and thymosin beta 4 applied on intact (not thymectomised) rats on the activities of the principle intrinsic pathway plasma clotting factors FXII, FXI, FIX and FX, and on the integral intrinsic pathway haemocoagulation parameter - activated partial thromboplastin time (aPTT).

\section{MATERIALS AND METHODS:}

The study was performed on 52 male Wistar strain rats. Rats weighing 200-220 g were bred under standard conditions at dark/light cycle 12/12 h, with free access to standard briquette chew and water. The animals were treated according to the requirements of the European Convention for the Protection of Experimental Animals (Protection of animals used for experimental purposes, Council Directive 86/609/EEC of November 1986) and Directive 2010/63/ EU of the European Parliament and of the Council of Europe, September 2010. The rats were divided into four equal groups (13 rats in a group) - one control and three experimental, and injected subcutaneously once daily in the time interval 08:00-09:00 $\mathrm{h}$ in the course of three consecutive days as follows: 1st group - by saline (the solvent of the peptides); 2nd group - by thymulin (Sigma Aldrich,0,4 mg/ kg b.m.); 3rd group - by thymosin alpha 1 (Sigma Aldrich,0,3 mg/kg b.m.); and the 4th group - by thymosin beta 4 (Sigma Aldrich,0,3 mg/kg b.m.). The peptides used were in the form of a dry substance and were dissolved $e x$ tempore. The doses used were defined on the bases of literature data, and through preliminary analyses or determination of logarithmic dose-effect dependence. Experiments were carried out during the period of the spring equinox. The observation period duration was 72 hours. The necessary blood volume from a rat $(4,5 \mathrm{ml})$ was obtained in a plastic single usage syringe by a cardiac puncture under urethane narcosis (blood/anticoagulant ratio 9:10). Sodium citrate $(0.11 \mathrm{~mol} / \mathrm{l})$ was used as an anticoagulant. Centrifuging dration was 10 minutes at $3000 \mathrm{rev} / \mathrm{min}$. The supernatant was separated and stored at $4{ }^{\circ} \mathrm{C}$ in haemostatic test-tubes. The coagulation parameter aPTT was determined not later than 2 hours by reactives of Diagnostica Stago, France. The rest of plasma was frozen and stored at $-60^{\circ} \mathrm{C}$ for plasma clotting factors measurement (FXII, FXI, FIX, and FX), which were evaluated not later than 10 days using Dade Behring (USA) reactives.

All parameters studied were determined on coagulometer Coag-Mate XM by conventional kinetic coagulometric methods applied elsewhere. At the end of the experiments, the animals were autopsied and macroscopically inspected for hemorrhages. Slices from the internal organs (kidney, liver, stomach and spleen) were prepared and stained by hematoxylin-eozyne and by Weigert for fibrin for the exclusion of micro-hemorrhages and/or intravascular coagulation.

All data were analysed by variation analysis, by Student-Fisher's t-test, using GraphPad Prism 5 software product. The results are presented as MEAN \pm SEM.Values of $p$ less than 0.05 were considered significant

\section{RESULTS:}

Figure 1 illustrates the effects on the activity of FXII presented in percent of the activity. Thymulin and thymosin alpha 1 significantly reduced FXII activity (respectively to $64.18 \pm 7.25$ and $85.92 \pm 7.49$ ) versus control group value $150.2 \pm 17.51$. Thymosin beta 4 application did not affect this parameter $(141.3 \pm 13.66)$ significantly.

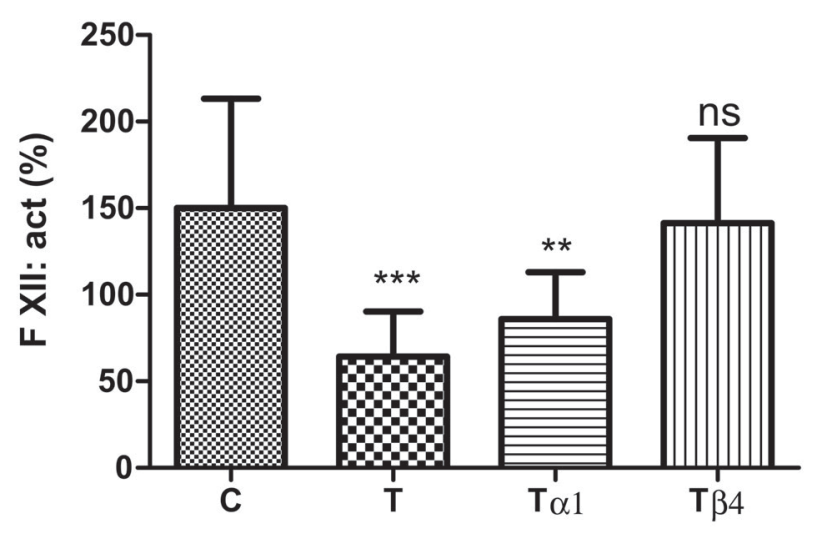

Fig. 1. Effects of thymulin $(0,4 \mathrm{mg} / \mathrm{kg}$ b.m.), thymosin alpha $1(0,3 \mathrm{mg} / \mathrm{kg}$ b.m. ) and thymosin beta $4(0,3$ $\mathrm{mg} / \mathrm{kg}$ b.m.) applied subcutaneously for three consecutive days on male Wistar rats on the activity (\%) of F XII (plasma clotting factor XII).

Data are presented as MEAN \pm SEM,

$* *$-p $<0,001, * * *$-p $<0,0001, \mathrm{C}$-control; T-thymulin; T $\alpha 1$-thymosin alpha 1 ; T $\beta 4$-thymosin beta 4 ; ns - non significant.

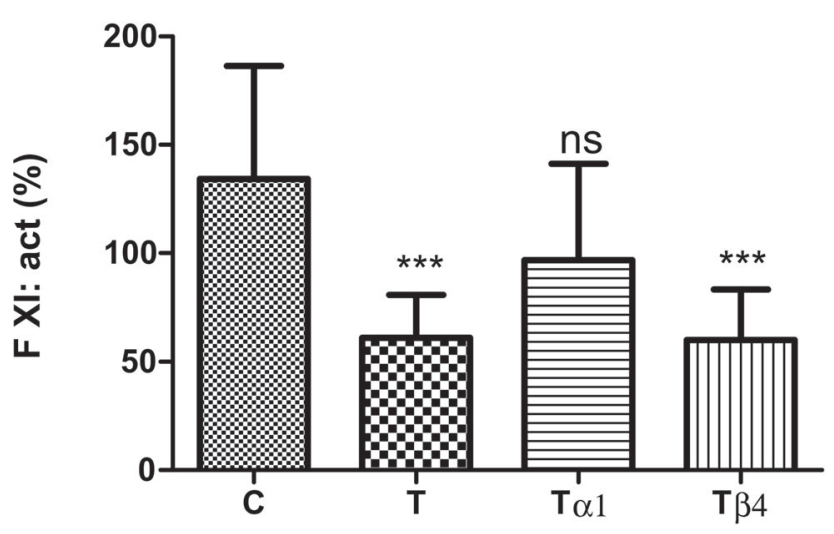

Fig. 2. Effects of thymulin $(0,4 \mathrm{mg} / \mathrm{kg} \mathrm{b.m.),}$ thymosin alpha $1(0,3 \mathrm{mg} / \mathrm{kg}$ b.m.) and thymosin beta $4(0,3$ $\mathrm{mg} / \mathrm{kg}$ b.m.) applied subcutaneously for three consecutive days on male Wistar rats on the activity (\%) of F XI (plasma clotting factor XI).

Data are presented as MEAN \pm SEM,

$* * *$ - $\mathrm{p}<0,0001, \mathrm{C}$-control; T-thymulin; T $\alpha 1-$ thymosin alpha 1 ; T $\beta 4$-thymosin beta 4 ; ns - non significant. 
FXI activity (fig. 2) was substantially suppressed from $134.3 \pm 14.47$ (control group) to $61.09 \pm 5.49$ (thymulin application) and respectively to $60.08 \pm 6.49$ (thymosin beta 4). Thymosin alpha 1 did not influence this parameter significantly $(96.83 \pm 12.32)$.

On the figure 3 are presented the effects of thymus peptides on FIX activity, which was decreased significantly respectively to $60.09 \pm 5.67$ (thymulin) and to $74.83 \pm$ 5.16 (thymosin beta 4 ), compared to controls (130.2 \pm 15.32), while thymosin alpha 1 did not cause any significant changes $(129.7 \pm 14.23)$.

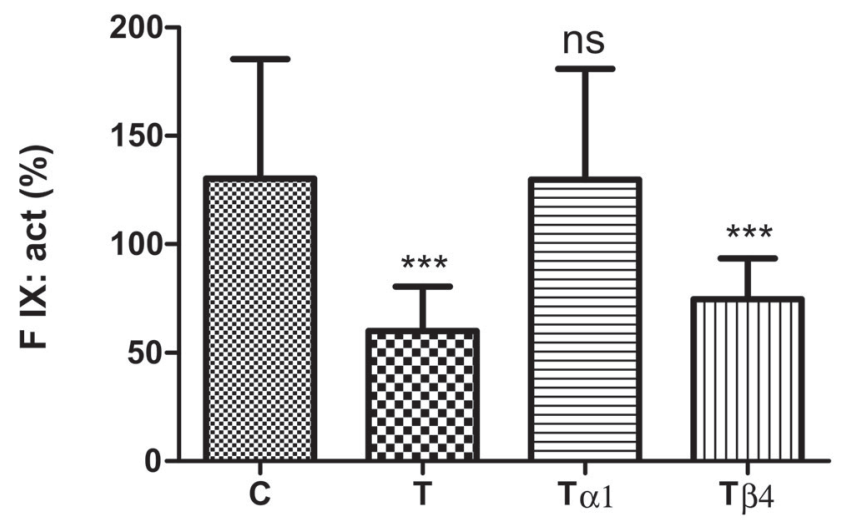

Fig. 3. Effects of thymulin $(0,4 \mathrm{mg} / \mathrm{kg}$ b.m. $)$, thymosin alpha 1 (0,3 mg/kg b.m.) and thymosin beta $4(0,3 \mathrm{mg} /$ $\mathrm{kg}$ b.m.) applied subcutaneously for three consecutive days on male Wistar rats on the activity (\%) of F IX (plasma clotting factor IX).

Data are presented as MEAN \pm SEM,

*** - $\mathrm{p}<0,0001, \mathrm{C}$-control; T-thymulin; T $\alpha 1$-thymosin alpha 1 ; T $\beta 4$-thymosin beta 4 ; ns - non significant.

Significant suppression of FX activity (fig. 4) was established by all the three thymus peptides, from $125.7 \pm$ 10.26 (control group), respectively to $60.03 \pm 6.50$ (thymulin), $70.31 \pm 5.10$ (thymosin alpha 1$)$ and $55.17 \pm 8.36$ (thymosin beta 4 ).

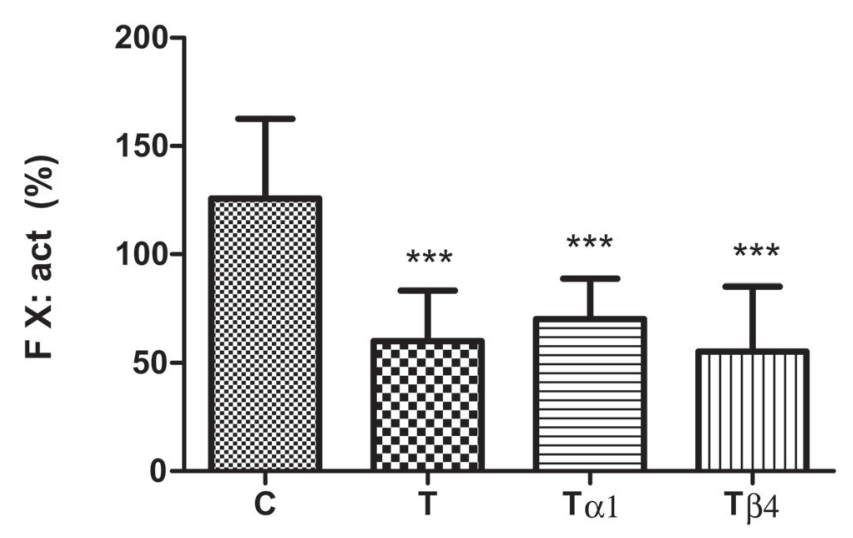

Fig. 4. Effects of thymulin (0,4 mg/kg b.m.), thymosin alpha $1(0,3 \mathrm{mg} / \mathrm{kg}$ b.m. $)$ and thymosin beta $4(0,3 \mathrm{mg} /$ $\mathrm{kg}$ b.m.) applied daily subcutaneously for three consecutive days on male Wistar rats on the activity (\%) of F X (plasma clotting factor $\mathrm{X}$ ).

Data are presented as MEAN \pm SEM,

$* * *-\mathrm{p}<0,0001, \mathrm{C}$-control; T-thymulin; T $\alpha 1-$ thymosin alpha 1 ; T $\beta 4$-thymosin beta 4 .

APTT (fig. 5) measured in seconds was significantly elongated by the three peptides respectively to $30.98 \pm 3.61$ sec (thymulin), 38.01 $\pm 5.24 \mathrm{sec}$.(thymosin alpha 1) and $35.10 \pm 3.03 \mathrm{sec}$. (thymosin beta 4 ), versus the control group $(18.79 \pm 0.94 \mathrm{sec}$.

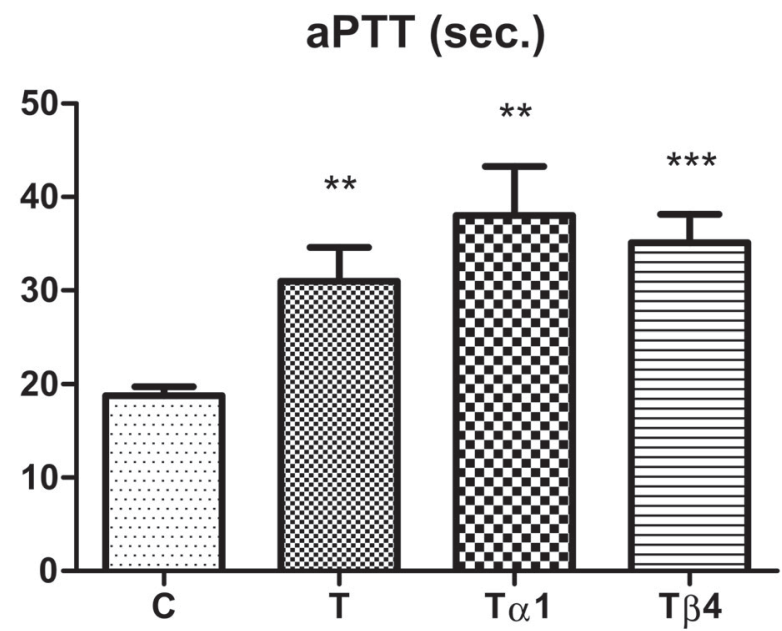

Fig. 5. Effects of thymulin $(0,4 \mathrm{mg} / \mathrm{kg} \mathrm{b.m.),}$ thymosin alpha $1(0,3 \mathrm{mg} / \mathrm{kg}$ b.m.) and thymosin beta4 (0,3 $\mathrm{mg} / \mathrm{kg}$ b.m.) applied subcutaneously for three consecutive days on male Wistar rats on activated partial thromboplastin time (aPTT).

Data are presented as $\mathrm{MEAN} \pm \mathrm{SEM}$,

$*_{*}$ - $<<0,001, * *_{-}$- $<<0,0001$, C-control; T-thymulin; T $\alpha 1$-thymosin alpha 1 ; T $\beta 4$-thymosin beta 4 .

Histological and macroscopic inspections of internal organs did not indicate any signs of intravascular thrombosis or haemorrhage.

\section{DISCUSSION:}

FXII is a plasma protein with molecular mass of 80 kDà, produced by the liver and activated at contact with the injured endothelial surface (subendothelial space, collagen, negative charges) [16]. FXII activation is the first step of coagulation "cascade" initiation via the intrinsic pathway of blood coagulation, and FXII is a key triggering factor which determines one of the basic clinical blood coagulation tests -aPTT. Moreover, FXIIa plays other additional important roles in the processes of fibrinolysis, angiogenesis, inflammation, etc. The two thymus peptides thymulin and thymosin alpha 1 strongly decreased FXII activity (fig. 1). This type of effect on the factor substantially involved in the triggering mechanisms of the intrinsic pathway of hemocoagulation is an evidence of inhibition at the starting point of the coagulation process. This 
phenomenon is a prerequisite for the development of hypocoagulability.

The thymus peptides produce similar effects on FXI and FIX (fig. 2 and 3). In the complex mechanism of contact activation of the intrinsic pathway, FXI is activated by FXIIa, and once activated FXIa in turn catalyzes FIX conversion into FIXa [7]. The expressed reduction of FXI and FX activities by thymulin and thymosin beta 4 application $(\mathrm{p}<0.0001)$, indicates inhibition of the coagulation process and suggests a lower rate of formation of the tenase complex (FIXa, FVIIIa, phospholipid membranes and calcium ions) - key elements in the activation of FXand formation of prothrombin activator. Those findings illustrate in turn even more defined tendency of hypocoagulability.

In clinical practice, FIX deficiency causes haemophilia type B, while deficiency of its co-factor FVIII causes haemophilia A associated with haemorrhages in joints, muscles and soft tissues [17]. FXI deficiency is a milder disorder mainly generating posttraumatic hemorrhages predominantly in tissues with a higher fibrinolytic activity. Patients with FXII deficiency do not manifest a bleeding tendency even during surgical interventions, although their noticeably elongated aPTT and clotting times [18]. There is a possibility of activation of FIX and FXI by an alternative mechanism from the complex TF/FVII and by thrombin which may explain the absence of hemorrhagic diathesis in patients with isolated FXII deficiency.

FXis a vitamin K-dependent glycoprotein synthesised in the liver, containing a light and a heavy chain. Its activation is based on splitting the Arg194-Ile195 in its heavy chain FX can be activated either by the intrinsic system (TF, FVIIa, $\mathrm{Ca}^{2+}$, phospholipids), or the intrinsic system ( FIXa, FVIIIa, $\mathrm{Ca}^{2+}$, phospholipids) [19]. The basic substrates of the powerful serine protease FX are prothrombin (FII), FV and FVII. FX activity is regulated by antithrombin which is its direct inhibitor. Tissue factor pathway inhibitor (TFPI)is a component of another inhibiting mechanism of $\mathrm{F} \mathrm{X}$ activation which operates indirectly by the formation of an inhibitory complex with tissue factor and FVIIa.FX deficiency is a rare disorder characterised by severe clinical signs: bleeding from soft tissues, central nervous system, gastrointestinal system, epistaxis, menorrhagia [20]. In this study, FX activity was significantly reduced $(p<0.0001)$ by the three thymus peptides (fig. 4). Factor X is a key player in blood coagulation common pathway after its formation by the intrinsic or extrinsic pathways. Its significantly suppressed activity is an evidence of a disbalanced hemostasis process towards hypocoagulability.

APTT is an integral blood coagulation parameter vastly dependent on the intrinsic pathway plasma clotting factors. APTT elongation is a substantial index of hypocoagulability. The results in figure 5 are in a good harmony with the results of plasma clotting factor activities discussed above. The expressed lengthening of aPTT by thymulin and thymosin alpha $1(\mathrm{p}<0.001)$ and thymosin beta $4(p<0.0001)$ is a generalized expression of the effects of plasma clotting factors envisaged and is a reliable confirmation of a tendency of reduced blood coagulability.

\section{CONCLUSION:}

The results of the present study evidence that thymus peptides thymulin, thymosin alpha 1 and thymosin beta 4 applied on intact rats express inhibitory effects on various levels of the hemocoagulation system via the intrinsic pathway. Thymulin and thymosin alpha 1 significantly reduce the activity of FXII, a key factor engaged in intrinsic pathway initiation, in this way suppressing the triggering mechanism of the intrinsic system. Thymulin and thymosin beta 4 substantially reduce activities of both FXI and FIX, a component of the internal tenase complex (FIX/ FVIII). The activity of FX, the key player in prothrombin complex, is suppressed by the three peptides. These findings explain the significant elongation aPTT and allow the assumption that thymus peptides thymulin, thymosin alpha 1 and thymosin beta 4 induce a noticeable tendency of hypocoagulability.

\section{REFERENCES:}

1. Davidson CJ, Hirt RP, Lal K, Snell P, Elgar G, Tuddenham EG, et al. Molecular evolution of the vertebrate blood coagulation network. Thrombo Haemost. 2003 Mar;89(3):420-8. [PubMed]

2. Versteeg HH, Heemskerk J, Levi M, Reitsma P. New Fundamentals in Hemostasis. Physiol Rev. 2013 Jan; 93(1):327-58 [PubMed] [CrossRef]

3. Dahlback B. Blood coagulation. Lancet. 2000 May 6;355(9215):162732. [PubMed] [CrossRef]

4. Long AT, Kenne E, Jung R, Fuchs $\mathrm{T}$, Renné $\mathrm{T}$. Contact system revisited: an interface between inflammation, coagulation, and innate immunity. $J$ Thrombosis Hemost. 2016 Mar;14(3) 427-37. [PubMed] [CrossRef]

5. Cheng Q, TuckerEI, Pine MS, Sisler I, Matafonov A, Sun MF, et al. A role for factor XIIa-mediated factor XI activation inthrombus formation in vivo. Blood. 2010 Nov 11; 116(19): 3981-9. [PubMed] [CrossRef]

6. Naudin C, Burillo E, Blankenberg S, Butler L, Renne T. Factor XII Contact Activation. Semin. Thromb. Hemostasis 2017 Mar 27, 0036. [PubMed] [CrossRef]

7. Gailani D, Renné T. Intrinsic pathway of coagulation and arterial thrombosis. Arterioscler Thromb Vasc Biol. 2007 Dec;27(12):2507-13. [PubMed] [CrossRef]

8. Soff GA. A new generation of oral direct anticoagulants. Arterioscler Thromb Vasc Biol. 2012 Mar; 32(3): 569-74. [PubMed] [CrossRef]

9. Meijers J, Tekelenburg W, Bouma B, Bertina R, Rosendaal F. High levels of coagulation factor XI as a risk factor for venous thrombosis. $N$ Engl J Med. 2000 Mar 9;342(10):696701. [PubMed] [CrossRef]

10. Eckman MH, Erban JK, Singh SK, Kao GS. Screening for the risk for bleeding or thrombosis. Ann Intern 
Med. 2003 Feb 4;138(3):W15-24. [PubMed]

11. Sié P, Steib A. Central laboratory and point of care assessment of perioperative hemostasis. Can $J$ Anaesth. 2006 Jun;53(6 Suppl):S1220. [PubMed]

12. Marshall JC. Inflammation, coagulopathy, and the pathogenesis of multiple organ dysfunction syndrome. Crit Care Med. 2001 Jul;29(7 Suppl): S99-106. [PubMed]

13. Squizzato A, Gerdes V, Ageno W, Buller HR. The coagulation system in endocrine disorders: a narrative review. Intern Emerg Med. 2007 Jun; 2(2):76-83. [PubMed] [CrossRef]

14. Franchini M, Lippi G, Manzato F, Vescovi PP, Targher G. Hemostatic abnormalities in endocrine and metabolic disorders. European J Endo- crinol. 2010 Mar;162(3):439-51. [PubMed] [CrossRef]

15. Goldstein AL, Hannappel E, Kleinman HK. Thymosin beta4: actinsequestering protein moonlights to repair injured tissues. Trends $\mathrm{Mol} \mathrm{Med}$. 2005 Sep;11(9):421-9. [PubMed] [CrossRef]

16. Renné T. The factor XII-driven plasma contact system. In: Hemostasis and Thrombosis: Basic Principles and Clinical Practice. Editors: Marder VJ, Aird WC, Bennett JS, Schulman S, White GC II. Lippincott Williams \& Wilkins. November 26, 2012. Chapter 15B: $120 \mathrm{p}$.

17. Lozier JN, Kessler CM. Clinical aspects and therapy of hemophilia. In: Hematology: Basic Principles and Practice. Editors: Hoffman R, Benz E, Shattil S, Furie B, Cohen H, Silberstein
L, McGlave P. New York: Churchill Livingstone. 2005. p.2047.

18. Kaplan AP. Intrinsic coagulation, thrombosis, and bleeding. Blood. 1996; 87(5):2090.

19. Palta S, Saroa R, Palta U. Overview of the coagulation system. Indian J Anaesth. 2014 Sep-Oct; 58(5): 515523. [PubMed] [CrossRef]

20. d'Audigier C, Delassasseigne $\mathrm{C}$, Robert A, Eschwège V. Underestimation of plasma level of factor $\mathrm{V}$ coagulant activity and fibrinogen concentration together with prolonged prothrombin time, activated partial thromboplastin time and thrombin time can result from pre-analytical very low calcium level in citrated sample tube. Int J Lab Hematol. 2016 Feb;38(1):50-3. [PubMed] [CrossRef]

Please cite this article as: Negrev N, Hristosov K, Hachmeryan A, Nyagolov Y. Thymus peptides (thymulin, thymosin alpha 1 and thymosin beta 4) inhibiting effects on the intrinsic blood coagulation pathway in ratsy. $J$ of IMAB. 2017 Jul-Sep;23(3):1641-1645. DOI: https://doi.org/10.5272/jimab.2017233.1641

Received: 22/05/2017; Published online: 04/08/2017

Corresponding author:

Yuri P. Nyagolov, Assoc. prof., MD, PhD.

Department of Physiology, Medical University, Sofia, Bulgaria

E-mail:nyagolv@abv.bg 